\title{
Zizyphus mauritiana extract-mediated green and rapid synthesis of gold nanoparticles and its antibacterial activity
}

\author{
Babak Sadeghi ${ }^{1}$
}

Received: 7 January 2015/Accepted: 18 March 2015/Published online: 9 April 2015

(c) The Author(s) 2015. This article is published with open access at Springerlink.com

\begin{abstract}
In this study, we have used Zizyphus mauritiana $(Z M)$ extracts and chloroauric acid $\left(\mathrm{HAuCl}_{4}\right)$ for synthesis of gold nanoparticles, with a particle size ranging from 20 to $40 \mathrm{~nm}$. The $Z M$ extract, acts both as reducing and stabilizing agent. UV-visible spectroscopy, X-ray diffraction (XRD), Fourier transform infra red spectroscopy (FTIR), transmission electron microscopy, scanning electron microscopy (SEM), and X-ray energy dispersive spectrophotometer were performed to ascertain the formation of Au-NPs. It was observed that the growths of Au-NPs are stopped within $25 \mathrm{~min}$ of reaction time. The synthesized Au-NPs were characterized by a peak at $535 \mathrm{~nm}$ in the UV-visible spectrum. XRD confirmed the crystalline nature of the nanoparticles of $27 \mathrm{~nm}$ size. The FTIR result clearly showed that the extracts containing $\mathrm{OH}$ as a functional group act in capping the nanoparticles synthesis. Antibacterial activities of Au-NPs were tested against the growth of Gram-positive ( $S$. aureus) using SEM. Therefore, green synthesis of gold nanoparticles with $Z M$ extract, is beneficial from its biological and medical applications.
\end{abstract}

Babak Sadeghi

b_sadeghi@toniau.ac.ir

1 Department of Chemistry, Tonekabon Branch, Islamic Azad University, Tonekabon, Iran
Graphical abstract

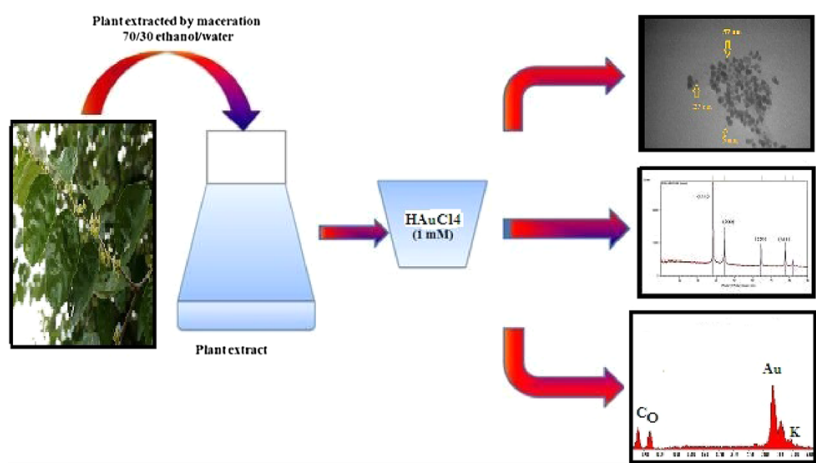

Keywords Gold nanoparticles - Green chemistry · Scanning electron microscopy (SEM) - Zizyphus mauritiana $(Z M) \cdot$ Antibacterial

\section{Introduction}

Biosynthesis of gold nanoparticles with small size and biostability is very important and used in various biomedical applications. Metallic nanoparticles of specific sizes and morphologies can be readily synthesized using chemical and physical methods [1-5]. Nanoparticles with small particle size and high surface to volume ratio exhibit new and unique properties in comparison with bulk materials, which make them particularly attractive for use in biomedical science. For this reason, in recent years a great deal of effort has been expended to use natural materials as benign reagents in nanoparticles synthesis [6-9]. Among green synthesis methods, the use of plants for nanoparticles synthesis could be advantageous over other environmentally 
benign approaches like microorganisms-based methods [ 6 , $7,10]$, as this eliminates the elaborate process of microorganism culture $[11,12]$ and the reaction time dramatically diminishes from several days to several hours.

Although the potential of some plants to produce nanoparticles has been investigated in the past few years $[11,13-18]$, research studies in this field are still in progress due to vast applications of nanoparticles in biology which make the use of green methods necessary.

Kumar and Yadav [12] have reviewed the use of plants and their extracts in the synthesis of metallic nanoparticles for various human applications.

The literature is replete with the investigations of the use of plants extracts [13], fungi [14], algae [15], proteins and enzymes [16] as the reductant for carrying out the syntheses of nanoparticles with a variety of shapes and morphologies in high yields, including multi-branched advanced gold and/or silver nanomaterials [17]; but the use of surfactant in the green synthesis of gold sol has been neglected. Because of the increasing environmental concerns by chemical synthesis routes, an environmentally sustainable synthesis process has led to biomimetic approaches, which refers to applying biological principles in materials formation. Bio-reduction is one of the fundamental processes in the biomimetic synthesis. The stability, shape, size, and morphologies of metal nanoparticles strongly depend on the method of preparation, type, nature of reductants, and concentration of stabilizers (polymers, ligands, solid matrix and surfactants) [18]. The surface plasmon resonance and large effective scattering cross section of individual gold nanoparticles make them ideal candidates for molecular labeling where phenomena such as surface-enhanced Raman scattering (SERS) can be exploited [19-25].
We have recently developed a reduction method of converting Ag nanospheres into nanorods [26], nanoplates [27], their antibacterial activity [28, 29], an improved an easy synthetic route for silver nanoparticles in poly (diallyldimethylammonium chloride) (PDDA) [30], synthesis of gold/HPC hybrid nanocomposite [31], preparation of $\mathrm{ZnO} /$ Ag nanocomposite [32] and comparison of nanosilver particles and nanosilver plates for the oxidation of ascorbic acid [33]. Regarding the role of green chemistry, we have successfully demonstrated that size, shape and the antibacterial activity gold nanoparticles by the reduction of $\mathrm{Au}^{3+}$ ions with bio-reductants Zizyphus mauritiana (ZM) largely depend on the nature of reducing agents, concentration and time of mixing of the reactants [34]. In addition, chemical methods employ toxic chemicals as reducing agents, or nonbiodegradable stabilizing agents and are therefore potentially dangerous to the environment and biological systems [35]. Moreover, most of these methods entail intricate controls or nonstandard. The methodology employed here is very simple, easy to perform, inexpensive, and eco-friendly (Scheme 1). Therefore, green synthesis of gold nanoparticles with $Z M$ extract, as an alternative to chemical synthesis, is beneficial from its biological and medical applications point of view, because of its high antibacterial efficacy and hence has a great potential in the preparation of drugs used against bacterial diseases and physiological stability.

\section{Materials and methods}

\section{Materials}

Chloroauric acid $\left(\mathrm{HAuCl}_{4}\right)$ was obtained from Sigma. All other reagents used in the reaction were of analytical grade
Scheme 1 Zizyphus mauritiana $(Z M)$ leaf extract reduces and stabilizes Au nanoparticles

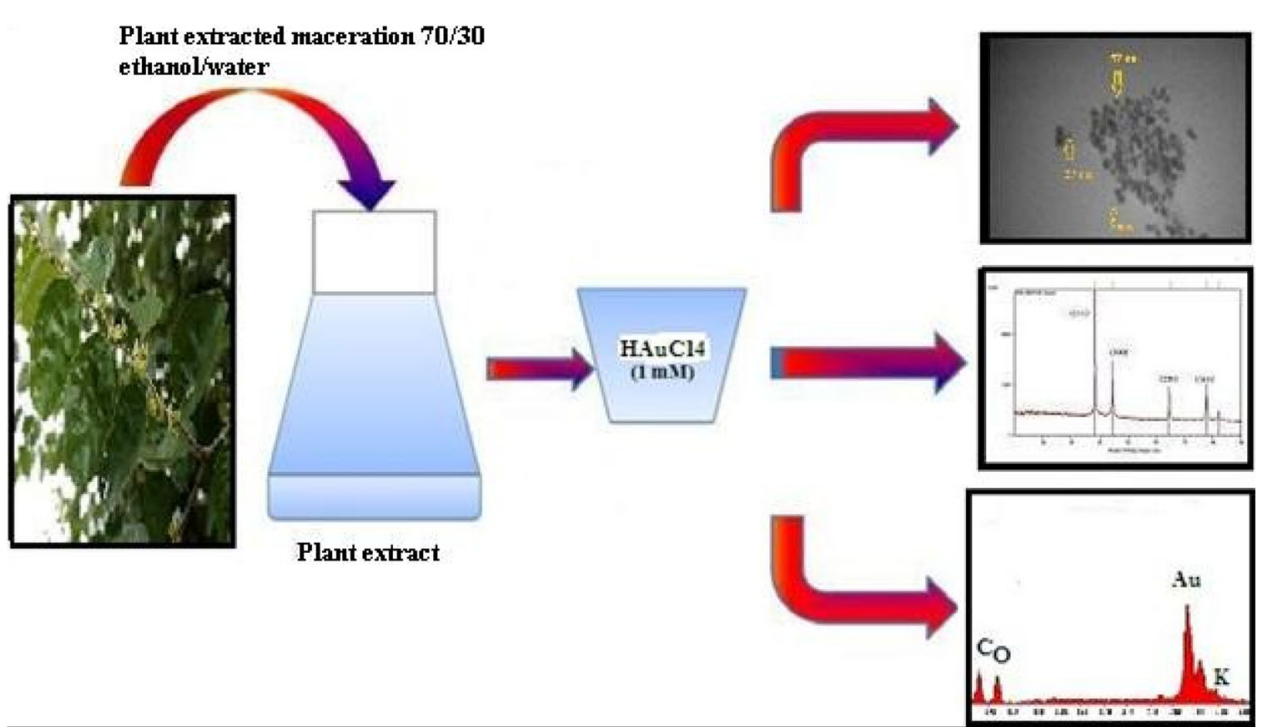


with maximum purity. $Z M$ leaves were collected from damavand of IRAN, and were cleaned with double distilled water and shade-dried for a week at room temperature and further $Z M$ leaves were ground to powder and stored for further study. For this experiment, nanoparticles have concentrations ranging from 0.0976 to $100 \mu \mathrm{g} \mathrm{mL}^{-1}$. S . aureus (ATCC 51153) was used as a Gram-positive bacterium. For the antimicrobial activity measurement, bacteria cultures were incubated at $38{ }^{\circ} \mathrm{C}$ in Luria medium (tryptone $1.5 \%$, yeast extract $0.75 \%$ sodium chloride $1.2 \%$, agar $1 \%$, Difco).

\section{Synthesis and characterization of gold nanoparticles} (Au-NPs)

In a typical reaction procedure, $Z M$ leaf extract was prepared by taking $2 \mathrm{~g}$ of dry leaf powder with $25 \mathrm{~mL}$ of distilled water in a conical flask along with $2 \mathrm{~mL}$ of methanol (minimum methanol was added to initiate the isolation of compounds). The extract was placed in orbital shaker for $1 \mathrm{~h}$ and the extract was filtered. For the synthesis of gold nanoparticles various concentrations of leaf extracts were tried and then the extract to be used was optimized to $1 \mathrm{~mL}$. Further, $1 \mathrm{~mL}$ of the extract was added to $10 \mathrm{~mL}$ of $1 \mathrm{mM}$ chloroauric acid $\left(\mathrm{HAuCl}_{4}\right)$ solution and the solution was placed in orbital shaker at room temperature, for reduction of $\mathrm{Au}^{3+}$ to $\mathrm{Au}^{0}$. The broth containing Au-NPs was centrifuged at 15,000 rpm for $20 \mathrm{~min}$, following which the pellet was re-dispersed in the sterile distilled water to get rid of any uncoordinated biological molecules. The color change involved in the formation of gold nanoparticles. The purified pellets were then kept into petri plates and left in the oven for drying at $60{ }^{\circ} \mathrm{C}$ for $24 \mathrm{~h}$. A color change was observed from colorless to purple to ruby red within $10 \mathrm{~min}$, indicated the formation of $\mathrm{Au}-$ NPs. The dried Au-NPs were scrapped out for the further study.

\section{Antimicrobial activity studies of the synthesized Au-NPs}

S. aureus (ATCC 51153) was used as a Gram-positive bacterium. For the antimicrobial activity measurement, bacteria cultures were incubated at $38{ }^{\circ} \mathrm{C}$ in Luria medium (tryptone $1.5 \%$, yeast extract $0.75 \%$, sodium chloride $1.2 \%$, agar $1 \%$, Difco).

Antimicrobial activities of gold nanoparticles (Au-NPs) have been investigated against $S$. aureus as the model Gram-positive bacteria. The in vitro antibacterial activities of gold nanoparticles were examined according Melaiye and Feng [36-38]. The following microorganism was used: Gram-positive $S$. aureus.

\section{Zeta potentiometer of the synthesized Au-NPs}

Stability of developed Au-NPs at different pHs was analyzed using Malvern Zetasizer (ZEN 3600). The pH of the synthesized nanoparticles solution was varied from $\mathrm{pH} 6$ to 12 by adjusting with $0.2 \mathrm{~N} \mathrm{HCl}$ and $0.2 \mathrm{~N} \mathrm{NaOH}$.

\section{Characterization of gold nanoparticles (Au-NPs)}

The biosynthesis of the Au-NPs in a solution was monitored by measuring the UV-Vis spectra of the solutions (1:4 diluted) of the reaction mixture. UV-Vis spectra were recorded on double beam spectrophotometer (Shimazdu, model UV-1800, Kyoto, Japan) from 300 to $800 \mathrm{~nm}$ at a resolution of $1 \mathrm{~nm}$. The distilled water was used as a blank. The Au-NPs synthesized with $8 \%$ leaf extracts and $8 \mathrm{mM}$ chloroauric acid $\left(\mathrm{HAuCl}_{4}\right)$ solution were characterized with the help of scanning electron microscopy (model LEO 440i) equipped with $\mathrm{X}$-ray energy dispersive spectrometer (EDAX) [36]. Transmission electron microscopy (TEM) selected area electron diffraction (SAED) images were taken on Zeiss-EM10C- $80 \mathrm{kV}$ operated at accelerating voltages of 40 and $200 \mathrm{kV}$. The observed reflection planes corresponding to fcc Au-NPs ( $27 \mathrm{~nm})$ in XRD diffraction pattern [Seisert Argon 3003 PTC using nickel-filtered $\mathrm{XD}-3 \mathrm{Cu}$ Ka radiations $(k=1.5418 \AA)$ ]. The purified powders of Au-NPs were subjected to FTIR spectroscopy (FTIR; Bomem MB100). These measurements were carried out on a Perkin-Elmer spectrum-one instrument in the diffuse reflectance mode at a resolution of $4 \mathrm{~cm}^{-1}$ in $\mathrm{KBr}$ pellets. For comparison, a drop of $8 \%$ leaf extracts was mixed with $\mathrm{KBr}$ powder and pelletized after drying properly. The pellets were later subjected to FTIR spectroscopy measurement.

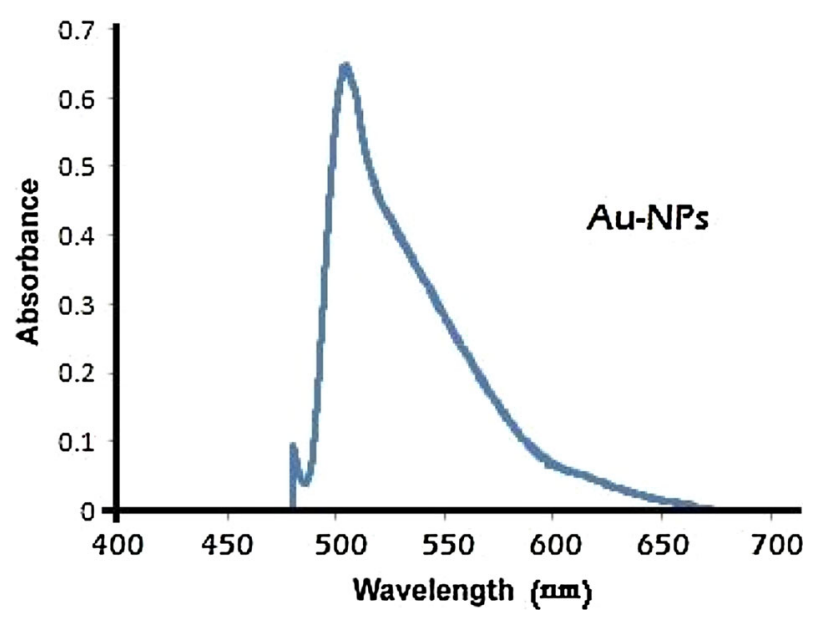

Fig. 1 UV-Vis spectra of an aqueous solution of Zizyphus mauritiana $(Z M)$ leaf extract in presence of $\mathrm{Au}^{3+}$ ions at $30^{\circ} \mathrm{C}$. Reaction conditions: $\left[\mathrm{Au}^{3+}\right]=10.0 \times 10^{-4} \mathrm{~mol} \mathrm{dm}^{-3}$ 

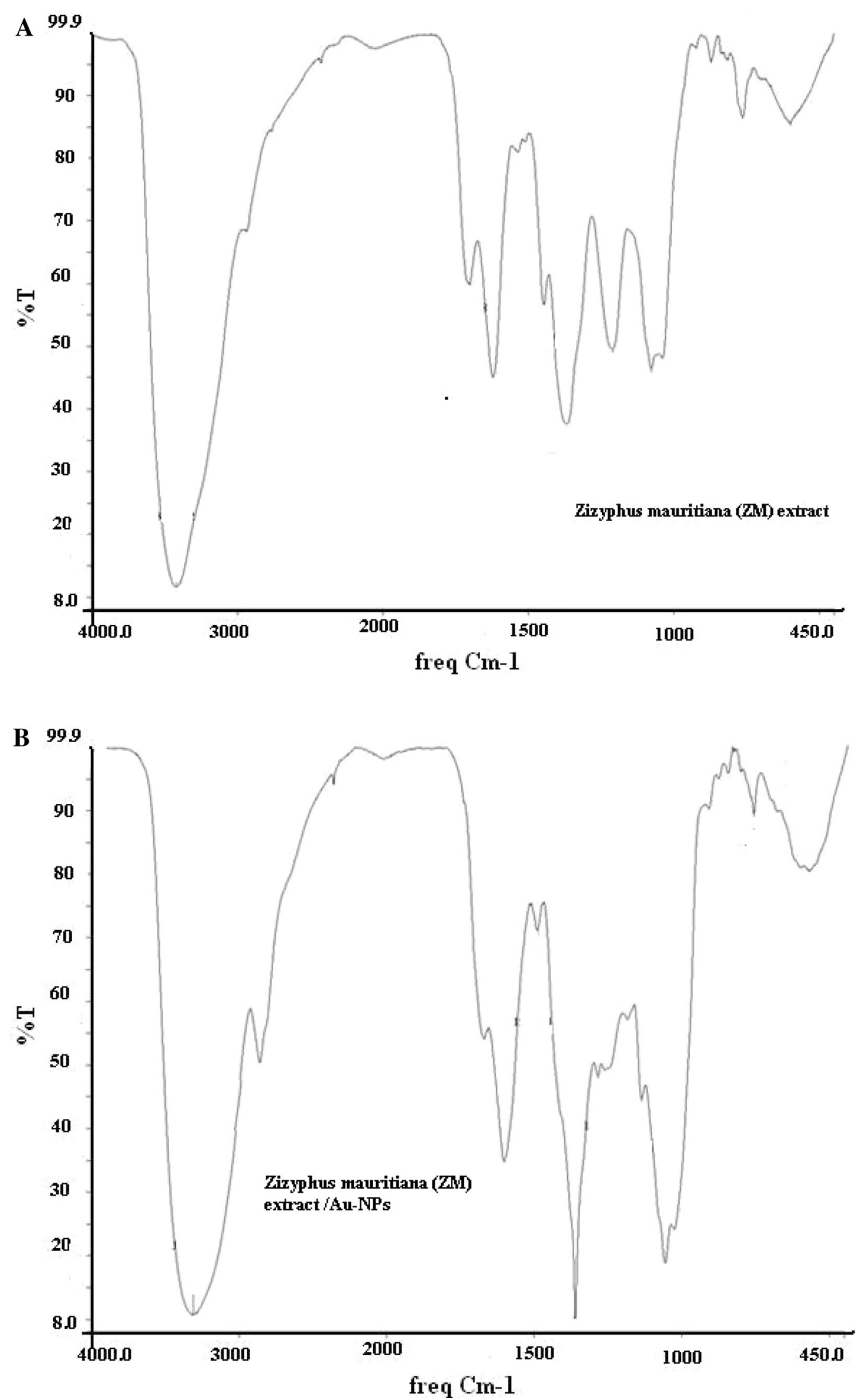

Fig. 2 FTIR spectra of Zizyphus mauritiana $(Z M)$ powder (a) before and after (b) reaction 
Fig. 3 TEM images indicating the presence of spherical gold nanoparticles recorded at various magnifications $(\mathbf{a}, \mathbf{b})$
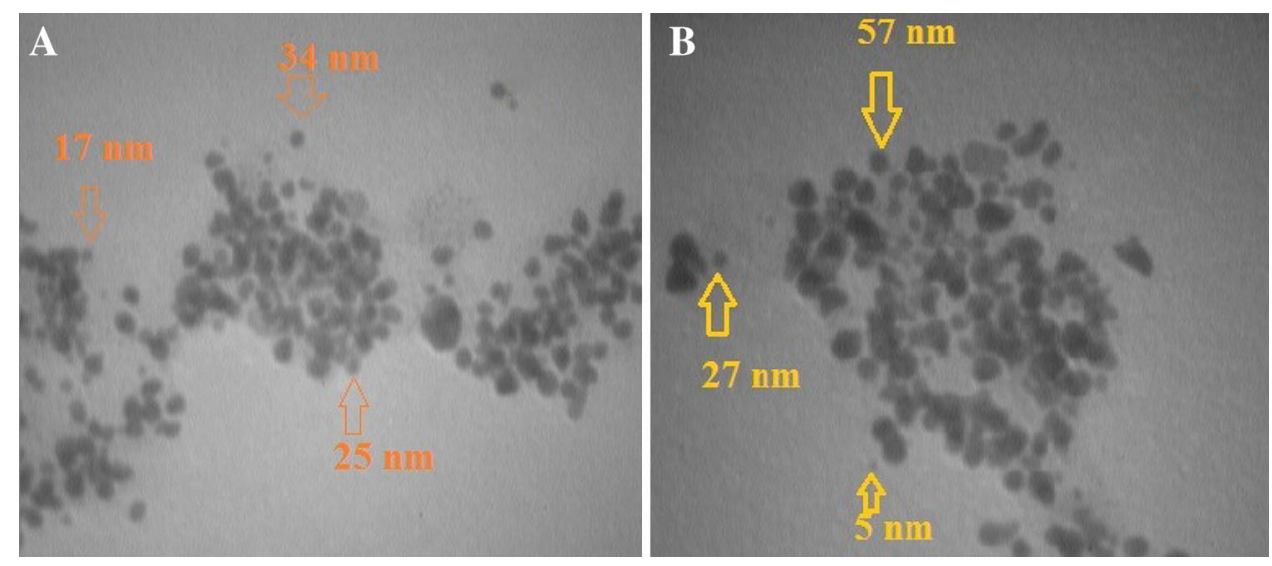
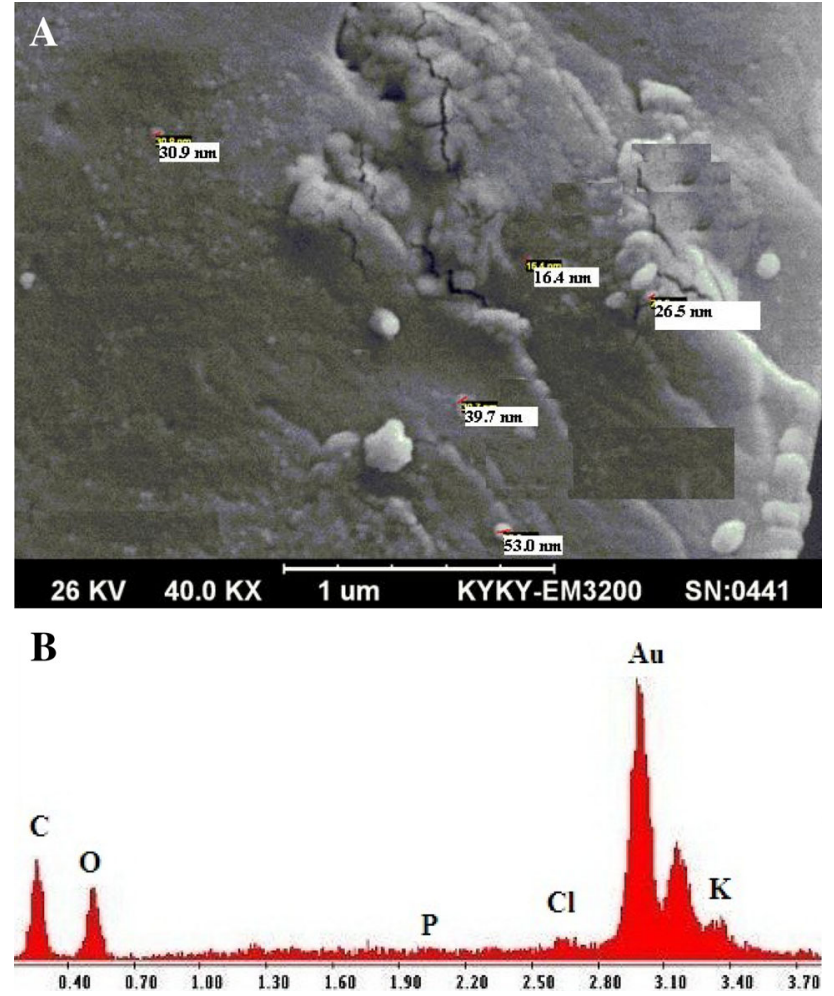

Fig. 4 a SEM and b EDAX images showing the presence of gold nanoparticles and bioorganic components of Zizyphus mauritiana $(Z M)$

\section{Results and discussion}

\section{UV-Vis spectral studies of the synthesized Au-NPs}

UV-Vis spectroscopy was ascertained to check the formation and stability of Au-NPs in aqueous solution (Fig. 1). The colorless chloroauric acid $\left(\mathrm{HAuCl}_{4}\right)$ solution turned purple to ruby red within $25 \mathrm{~min}$ indicated the formation of Au-NPs. The appearance of the brown color was due to the excitation of the surface plasmon resonance
(SPR), typical of Au-NPs having $\lambda_{\max }$ values which were reported earlier in the visible range of $530-550 \mathrm{~nm}$ [39] (Fig. 1). The SPR absorbance was extremely sensitive to the nature, size and shape of the particles formed, their inter particle.

\section{FTIR studies of the Zizyphus mauritiana (ZM) and synthesized Au-NPs}

FTIR measurements were carried out to identify the possible biomolecules responsible for reduction, capping and efficient stabilization of the Au nanoparticles. $Z M$ is rich in proteins and have high availability of the amino acids [40]. The representative FTIR spectra of the control extract and $Z M$ and stabilized gold nanoparticles were shown in Fig. 2. It can be seen that, in contrast to the control $Z M$ extract, the stabilized nanoparticles show significant changes in their respective vibrational spectra.

The interaction of Au nanoparticles with biomolecules of $Z M$ showed intense peaks at 2935, 1629, 1515, 1384, 1156,1076 and $1307 \mathrm{~cm}^{-1}$ relative shift in position and intensity distribution were confirmed with FTIR (Fig. 2a, b) recorded for dry powder of $Z M$, where the strong bands were observed at 1702, 1622 and $1446 \mathrm{~cm}^{-1}$. Comparing both FTIR spectra it can be identified that the changes in the $-\mathrm{COOH}$ group for $-\mathrm{OH}$, i.e., hydroxyl group the peak appeared at $3421 \mathrm{~cm}^{-1}$ in raw material, but after encapsulation of nanoparticles, the peak is narrower and shifted to $3391 \mathrm{~cm}^{-1}$ and also for $-\mathrm{C}-$ of carboxylic group the peak intensity reduced after encapsulation of nanoparticles. The band appearing at $1384 \mathrm{~cm}^{-1}$ corresponds to $\mathrm{C}-\mathrm{N}$ stretching of amine group [41] and in the raw extract the peak was broad and blend, but after encapsulation of nanoparticles the peak was narrow and sharper. This implies that $-\mathrm{COOH}$ group in the compound is attached to the gold nanoparticles and there in a clear change in the spectra. $1702 \mathrm{~cm}^{-1}$ in $-\mathrm{C}-$ bond stretching after the encapsulation this stretching is masked or disappeared. 
Fig. 5 XRD pattern of gold nanoparticles obtained using Zizyphus mauritiana (ZM)

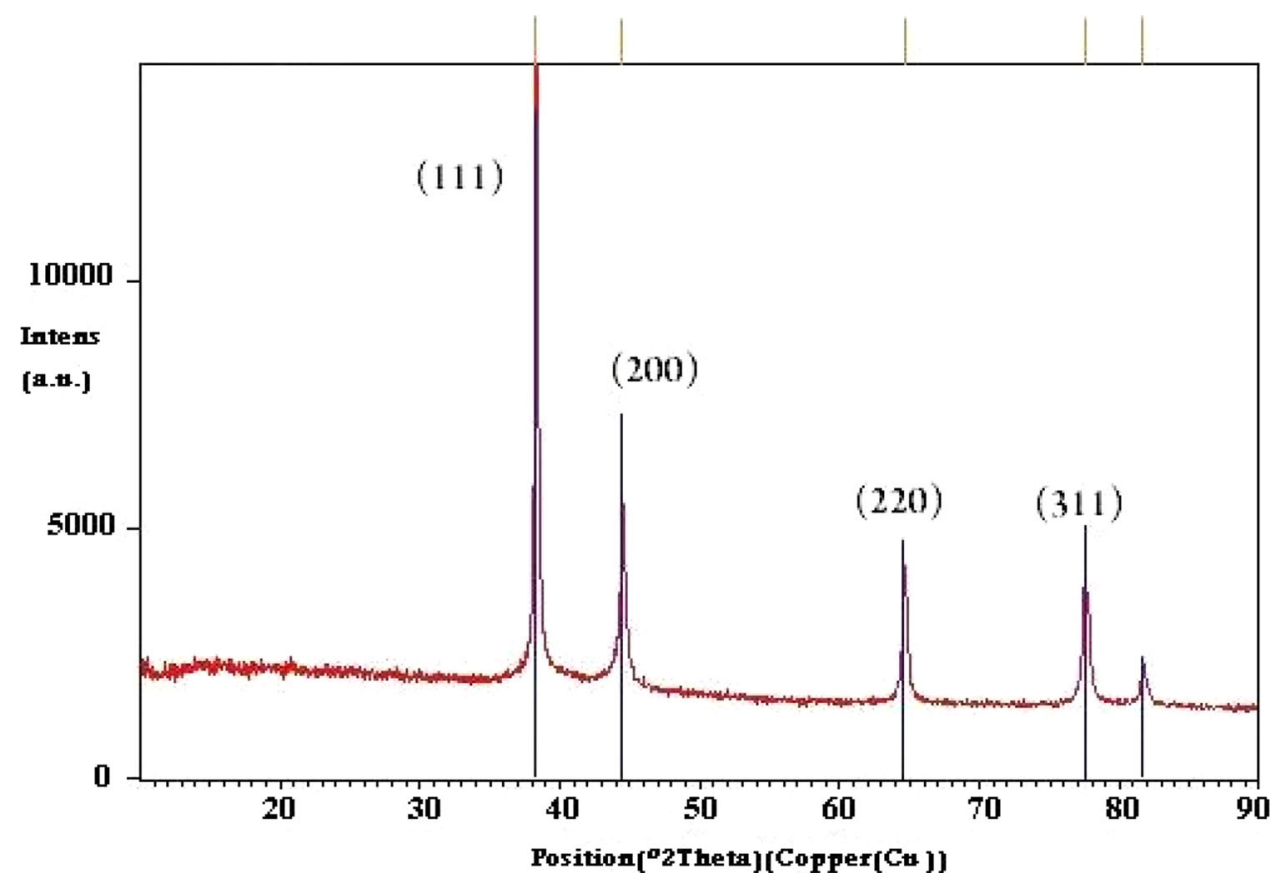

The absorption peak at $3421 \mathrm{~cm}^{-1}$ observed in control extract, which is due to $\mathrm{OH}$ stretching vibration, gets wider and shifted to $3391 \mathrm{~cm}^{-1}$. This peak was assigned to the $\mathrm{N}-\mathrm{H}$ group from protein present in the control extract. The $\mathrm{N}-\mathrm{H}$ vibrational bands become weaker and broader in the spectrum of stabilized $\mathrm{Au}$ nanoparticles. The IR bands at 1702 and $1622 \mathrm{~cm}^{-1}$ are characteristic of amide I whereas the band at $1515 \mathrm{~cm}^{-1}$ is characteristic of amide II, respectively $[8,42,43]$. In Fig. $2 b$, the two IR peaks of amide I were merged in one peak centered at $1629 \mathrm{~cm}^{-1}$. These structural changes indicated that the reduction and stabilization of gold nanoparticles proceed via the coordination between $\mathrm{N}$ of the amide group and gold ions. The FTIR studies have confirmed the fact that the amide group form proteins has the stronger ability to bind metal indicating that the proteins could possibly form a layer covering the metal nanoparticles (i.e., capping of gold nanoparticles) to prevent agglomeration and thereby stabilize the medium. Comparison between spectra of untreated sample to the treated samples Au-NPs reveal only minor changes in the positions as well as on the magnitude of the absorption bands; wave numbers varying typically about \pm 1 to $15 \mathrm{~cm}^{-1}$.

\section{TEM of the synthesized Au-NPs}

Figure 3 shows the TEM images of the gold nanoparticles synthesized using different $Z M$ leaf broth concentration (10\%) $1 \mathrm{mM} \mathrm{HAuCl}_{4}$ at $60{ }^{\circ} \mathrm{C}$ for $30 \mathrm{~min}$. The morphology and size of the synthesized gold nanoparticles were

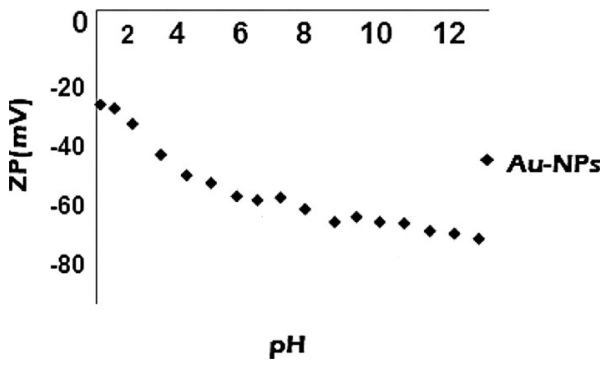

Fig. 6 Zeta potential at different $\mathrm{pH}$

determined by TEM images and they are shown in Fig. 3a, b. The particles formed were spherical in shape. The nanospherical formed where shown to have high surface area. The nanoparticles formed were in the range of $20-40 \mathrm{~nm}$ in size with $32 \mathrm{~nm}$ average size. The particles were monodisperse, with only a few particles of different size.

\section{SEM of the synthesized Au-NPs}

scanning electron microscopy (SEM) micro-graphs show aggregates of gold nanoparticles and the particles are in the range of 15-35 $\mathrm{nm}$ and they are not in direct contact even within the aggregates indicating the stabilization of nanoparticles by capping agents (Fig. 4a). In EDAX strong signals were observed from the gold atoms in the nanoparticles and weaker signals for carbon, oxygen, potassium and chloride were provenients from biomolecules of $Z M$ (Fig. 4b). 
Fig. 7 Representative SEM images showing reduced $S$. aureus colonization on Au-Nps/ extract (b) compared to extract (a). Arrows show bacteria
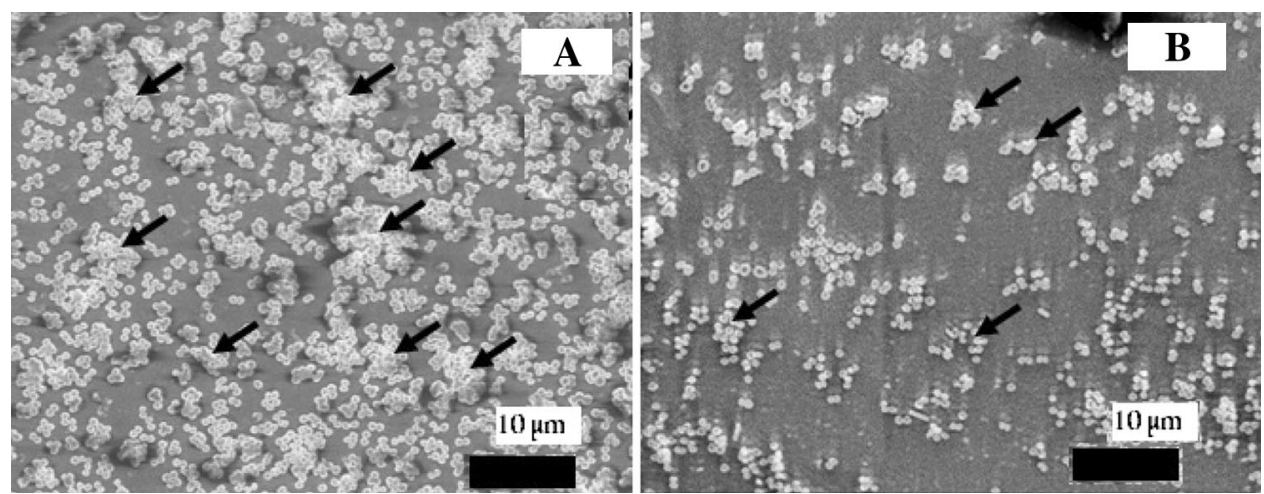

\section{XRD of the synthesized Au-NPs}

The crystalline nature of Au-NPs was carried out using XRD where three diffraction peaks were observed in the $2 \theta$ range of $30^{\circ}-80^{\circ}$, which can be indexed as ( $\left.\begin{array}{lll}1 & 1 & 1\end{array}\right),\left(\begin{array}{lll}2 & 0 & 0\end{array}\right)$, (2 20 ), (3 111 ) reflections of fcc structure metallic gold, respectively similar to Joint Committee on Powder Diffraction Standards (JCPDS) file no: ICDD-PDF2, Release 2007, PA, USA, 2007, revealing that synthesized AuNPs are of pure crystalline gold. The XRD patterns in (Fig. 5) of Au-NPs obtained were similar to the results reported earlier [44]. The XRD peaks at $38^{\circ}, 44^{\circ}, 64^{\circ}$ and $77^{\circ}$ can be indexed to the (1 111$),\left(\begin{array}{lll}2 & 0 & 0\end{array}\right),\left(\begin{array}{lll}2 & 2 & 0\end{array}\right)$ and (3 111$)$ Bragg's reflections of cubic structure of metallic gold, respectively. The particle size of the Au-NPs formed were calculated using Debye-Scherrer equation which was around $27 \mathrm{~nm}$, were good in agreement with TEM results also.

\section{Stability of the synthesized Au-NPs}

Stability of bio-synthesized Au-NPs was evaluated with zeta potentiometer at different $\mathrm{pH}$ after the synthesis of the metal nanoparticles (Fig. 6). It can be noted that synthesized Au-NPs were stable in a wider range of $\mathrm{pH}$ from 6 to 12. With increase in $\mathrm{pH}$, the value of zeta potential of $\mathrm{Au}-$ NPs increases from -22.3 to $-65.0 \mathrm{mV}$. It was notable that Au-NPs found stable in $\mathrm{pH}$ range from 6 to 12 (ZP value varied from -58.4 to $-65 \mathrm{mV}$ ) but $\mathrm{pH} 12$ found more stable. Leaves extract mediated synthesized Au-NPs and have high negative zeta potential values and thus they are stable under a wide $\mathrm{pH}$ range.

\section{Antimicrobial activity of gold nanoparticles}

We have investigated the use of these $Z M$-mediated gold nanoparticles as possible antibacterial agents. Such $Z M$ mediated gold nanoparticles were immediately tested for antimicrobial activity towards test bacterial strains. Figure $7 \mathrm{a}, \mathrm{b}$ shows the zones of inhibition that were observed with the $S$. aureus. In all these figures, the black arrows indicate the $S$. aureus colonization. This is consistent with an earlier report on the antimicrobial activity of gold nanoparticles bio-synthesized [36-38, 45], as well as those synthesized chemically [31]. In the present study, the nanoparticles thus synthesized could also be applied as selective antibacterial agents. The SEM indicated that, the most strains of $S$. aureus were damaged and extensively disappeared by addition of Au-NPs.

\section{Conclusion}

To conclude, the Au-NPs were produced by the use of the extract of $Z M$ as reducing and capping agent. In this study, it was observed that the reaction is rapid and is completed within $25 \mathrm{~min}$ at room temperature. We have demonstrated an eco-friendly, rapid green chemistry approach for the synthesis of Au-NPs using $Z M$, which provides a simple, cost effective and efficient way for the synthesis of AuNPs. Average crystal size calculated from Scherrer equation is found $27 \mathrm{~nm}$ for Au-NPs. The spectroscopic characterizations from UV-Vis, FTIR, TEM and zeta potential support the formation and stability of the bio-synthesized Au-NPs. This simple, efficient and rapid green synthesis of Au-NPs can be used in various biomedical and biotechnological applications. Therefore, this reaction pathway satisfies all the conditions of a $100 \%$ green chemical process. The SEM indicated that, the most strains of $S$. aureus were damaged and extensively disappeared by addition of Au-NPs. Thus, the synthesized Au-NPs could have a high potential for use in biological applications.

Acknowledgments The financial and encouragement support provided by the Tonekabon Branch, Islamic Azad University, Tonekabon, and Executive Director of Iran-Nanotechnology Organization (Govt. of Iran).

Open Access This article is distributed under the terms of the Creative Commons Attribution License which permits any use, distribution, and reproduction in any medium, provided the original author(s) and the source are credited. 


\section{References}

1. Sun, Y., Mayers, B., Herricks, T., Xia, Y.: Polyol synthesis of uniform silver nanowires: a plausible growth mechanism and the supporting evidence. Nano Lett. 3, 955-960 (2003)

2. Srikanth, H., Hajndl, R., Chirinos, C., Sanders, J.: Magnetic studies of polymer-coated Fe nanoparticles synthesized by microwave plasma polymerization. Appl. Phys. Lett. 79, 3503-3505 (2001)

3. Valle-Orta, M., Díaz, D., Santiago, P., Reguera, E., VázquezOlmos, A.: Instantaneous synthesis of stable zero-valent metal nanoparticles under standard reaction conditions. J. Phys. Chem. B 112, 14427-14434 (2008)

4. Guo, L., Huang, Q., Li, X., Yang, S.: Iron nanoparticles: synthesis and applications in surface enhanced Raman scattering and electrocatalysis. Phys. Chem. Chem. Phys. 3, 1661-1665 (2001)

5. Alqudami, A., Annapoorni, S.: Fluorescence from metallic silver and iron nanoparticles prepared by exploding wire technique. Plasmonics 2(7), 5-13 (2007)

6. Ahmad, A., Senapati, S., Khan, M.I., Kumar, R., Sastry, M.: Extracellular biosynthesis of monodisperse gold nanoparticles by anovel extremophilic actinomycete, Thermomonospora sp. Langmuir 19, 3550-3553 (2003)

7. Ahmad, A., Senapati, S., Khan, M.I., Kumar, R., Sastry, M.: Extra/intracellular, biosynthesis of gold nanoparticles by an alkalotolerant fungus, Trichotecium sp. J. Biomed. Nanotechnol. 1, 47-53 (2005)

8. Philip, D.: Honey mediated green synthesis of silver nanoparticles. Spectrochim. Acta A 78, 327-331 (2011)

9. Thakkar, K.N., Mhatre, S.S., Parikh, R.Y.: Biological synthesis of metallic nanoparticles. Nanomed. NBM 6, 257-262 (2010)

10. Juibari, M.M., Abbasalizadeh, S., Jouzani, G.S., Noruzi, M.: Intensified biosynthesis of silver nanoparticles using a native extremophilic Ureibacillus thermosphaericus strain. Mat. Lett. 65, 1014-1017 (2011)

11. Shankar, S.S., Rai, A., Ahmad, A., Sastry, M.: Rapid synthesis of $\mathrm{Au}, \mathrm{Ag}$, and bimetallic $\mathrm{Au}$ core $\mathrm{Ag}$ shell nanoparticles using neem (Azadirachta indica) leaf broth. J. Coll. Interf. Sci. 275, 496-502 (2004)

12. Kumar, V., Yadav, S.K.: Plant-mediated synthesis of silver and gold nanoparticles and their applications. J. Chem. Technol. Biotechnol. 84, 151-157 (2009)

13. Chandran, S.P., Chaudhary, M., Pasricha, R., Ahmad, A., Sastry, M.: Synthesis of gold nanotriangles and silver nanoparticles using Aloe vera plant extract. Biotechnol. Prog. 22, 577-583 (2006)

14. Kumar, P., Senthamil Selvi, S., Govindaraju, M.: Seaweed-mediated biosynthesis of silver nanoparticles using Gracilaria corticata for its antifungal activity against Candida spp. Appl. Nanosc. 3, 495-500 (2013)

15. Huang, J., Li, Q., Sun, D., Lu, Y., Su, Y., Yang, X., Wang, H., Wang, Y., Shao, W., Hong, N.J., Chen, C.: Biosynthesis of silver and gold nanoparticles by novel sundried Cinnamomum camphora leaf. Nanotechnology 18, 105104-105115 (2007)

16. Song, J.Y., Jang, H.K., Kim, B.S.: Biological synthesis of gold nanoparticles using Magnolia kobus and Diopyros kaki leaf extracts. Process Biochem. 44, 1133-1138 (2009)

17. Dubey, S.P., Lahtinen, M., Sillanpaa, M.: Tansy fruit mediated greener synthesis of silver and gold nanoparticles. Process Biochem. 45, 1065-1071 (2010)

18. Narayanan, K.B., Sakthivel, N.: Phytosynthesis of gold nanoparticles using leaf extract of Coleus amboinicus Lour. Mater. Charact. 61, 1232-1238 (2010)

19. Singhal, G., Bhavesh, R., Kasariya, K., Sharma, A.R., Singh, R.P.: Biosynthesis of silver nanoparticles using Ocimum sanctum, Tulsi leaf extract and screening its antimicrobial activity. J. Nanopart. Res. 13, 2981-2988 (2011)
20. Duran, N., Marcato, P.D., De Souza, G.I.H., Alves, O.L., Esposito, E.: Mechanistic aspects of biosynthesis of silver nanoparticles by several Fusarium oxysporum strains. J. Biomed. Nanotechnol. 3, 1-8 (2009)

21. Xie, J., Lee, J.Y., Wang, D.I.C., Ting, Y.P.: Identification of active biomolecules in the high-yield synthesis of single-crystalline gold nanoplates in algal solutions. Small 3, 672-682 (2007)

22. Zhou, Y., Chen, W., Itoh, H., Naka, K., Ni, Q., Yamane, H., Chujo, Y.: Preparation of a novel core-shell nanostructured gold colloid-silk fibroin bioconjugate by the protein in situ redox technique at room temperature. Chem. Commun. 23, 2518-2519 (2001)

23. Zhai, X., Efrima, S.: Silver colloids and macroemulsions of metal interfacial colloidal films: interaction with dithizone. J. Phys. Chem. 100, 10235-10242 (1996)

24. El-Sayed, M.A.: Some interesting properties of metals confined in time and. nanometer space of different shapes. Acc. Chem. Res. 34, 257-264 (2001)

25. Šileikaite, A., Prosyčevas, I., Puišo, J., Juraitis, A., Guobiene, A.: Analysis of silver nanoparticles produced by chemical reduction of silver salt solution. Mater. Sci. 12, 287-291 (2006)

26. Sadjadi, M.A.S., Sadeghi, B., Meskinfam, M., Zare, K., Azizian, J.: Synthesis and characterization of Ag/PVA nanorods by chemical reduction method. Physica E Low Dimens. Syst. Nanostruct. 40, 3183-3186 (2008)

27. Sadeghi, B., Sadjadi, M.A.S., Vahdati, R.A.R.: Nanoplates controlled synthesis and catalytic activities of silver nanocrystals. Superlattices Microstruct. 46, 858-863 (2009)

28. Sadeghi, B., Jamali, M., Kia, S.H., Amini Nia, A., Ghafari, S.: Synthesis and characterization of silver nanoparticles for antibacterial activity. Int. J. Nano Dimens. 1, 119-124 (2010)

29. Sadeghi, B., Garmaroudi, F.S., Hashemi, M., Nezhad, H.R., Nasrollahi, A., Ardalan, S., Ardalan, S.: Comparison of the antibacterial activity on the nanosilver shapes: nanoparticles, nanorods and Nanoplates. Adv. Powder Tech. 23, 22-26 (2012)

30. Sadeghi, B., Pourahmad, A.: Synthesis of silver/poly (diallyldimethylammonium chloride) hybrid nanocomposite. Adv. Powder Tech. 22, 669-673 (2012)

31. Sadeghi, B., Ghammamy, S.H., Gholipour, Z., Ghorchibeigy, M., Amininia, A.: Gold/HPC hybrid nanocomposite constructed with more complete coverage of gold nano-shell. Mic Nano Lett. 6, 209-213 (2011)

32. Sadeghi, B.: Preparation of $\mathrm{ZnO} / \mathrm{Ag}$ nanocomposite and coating on polymers for anti-infection biomaterial application. Spectrochim. Acta Part A Mol. Biomol. Spectrosc. 118, 787-792 (2014)

33. Sadeghi, B., Meskinfam, M.: A direct comparison of nanosilver particles and nanosilver plates for the oxidation of ascorbic acid. Spectrochimica Acta Part A Mol. Biomol. Spectrosc. 97, 326-328 (2012)

34. Umesh, B., Jagtap, V., Bapat, A.: Green synthesis of silver nanoparticles using Artocarpus heterophyllus Lam. seed extract and its antibacterial activity. Ind. Crops Prod. 46, 132-137 (2013)

35. Nadagouda, M.N., Hoag, G., Collins, J., Varma, R.S.: Green synthesis of $\mathrm{Au}$ nanostructures at room temperature using biodegradable plant surfactants. Cryst. Growth Des. 9, 4979-4983 (2009)

36. Bankar, A., Joshi, A.B., Ravi Kumar, M., Zinjarde, S.: Banana peel extract mediated synthesis of gold nanoparticles. Colloids Surf. B Biointerfaces. 80, 45-50 (2010)

37. Panthong, A., Supraditaporn, W., Kanjanapothi, D., Taesotikul, T., Reutrakul, V.: Analgesic, anti-inflammatory and venotonic effects of Cissus quadrangularis Linn. J. Ethnopharmacol. 110, 264-270 (2007) 
38. Rajendiran, J.R., Rahuman, A., Perumal, P.: Green synthesis of gold nanoparticles using seed aqueous extract of Abelmoschus, esculentus and its antifungal activity. Ind. Crops Prod. 45, 423-429 (2013)

39. Sastry, M., Mayyaa, K.S., Bandyopadhyay, K.: pH dependent changes in the optical properties of carboxylic acid derivatized silver colloid particles. Colloids Surf. A 127, 221-228 (1997)

40. Wang, X., Bunkers, G.J.: Potent heterologous antifungal proteins from cheeseweed (Malva parviflora). Biochem. Biophys. Res. Commun. 279, 669-673 (2000)

41. Badri Narayanan, K., Sakthivel, N.: Coriander leaf mediated biosynthesis of gold nanoparticles. Mater. Lett. 62, 4588-4590 (2008)
42. He, S., Zhang, Y., Guo, Z., Gu, N.: Biological synthesis of gold nanowires using extract of Rhodopseudomonas capsulate. Biotechnol. Prog. 24, 476-480 (2008)

43. Basavaraja, S., Balaji, S.D., Lagashetty, A., Rajasab, A.H., Venkataraman, H.: Extracellular biosynthesis of silver nanoparticles using the fungus Fusarium semitectum. Mater. Res. Bull. 43, 1164-1170 (2008)

44. Straumanis, M.E.: The preparation of gold nanoparticle composites using supercritical carbon dioxide. J. Monatshefte Fuer. Chemie. 102, 1377-1386 (1971)

45. Chaloupka, K., Malam, Y., Seifalian, A.M.: Nanosilver as a new generation nanoproduct in biomedical applications. Trends Biotechnol. 28, 580-588 (2010) 